\title{
A DINÂMICA DOS SISTEMAS LITORAIS DO SUL DE MOÇAMBIQUE DURANTE OS ÚLTIMOS 30 ANOS
}

\author{
Maria EugÉnia Moreira ${ }^{1}$
}

\begin{abstract}
Resumo - A erosão é o fenómeno que domina a dinâmica actual dos sistemas litorais de Moçambique, onde, em mais de $90 \%$ da extensão da costa, é devida a causas naturais. A passagem de depressões e ciclones tropicais, e a elevação recente do nível médio do oceano são as causas fundamentais. A transgressão oceânica manifesta-se no estreitamento das praias, no entalhe dos cordões dunares que migram para o interior, assoreando as lagunas anexas, na segmentação das restingas e ilhas-barreira, no recuo rápido das arribas vivas e na reactivação das mortas, no desmantelamento das microformas de bio-erosão das plataformas areníticas da faixa entre-marés, no estreitamento dos mangais, na salinização dos aquíferos salobros das planícies litorais e das ilhas, e no crescimento dos recifes coralígenos. São apresentados exemplos da região costeira do Sul de Moçambique, onde se observam taxas médias de recuo da linha de costa de $0,11 \mathrm{~m}$ a $1,10 \mathrm{~m} / \mathrm{ano}$, entre 1971-1975 e 1999-2004, respectivamente em praias abrigadas e expostas à ondulação oceânica, com dinâmica natural. Todavia, as taxas de erosão mais elevadas, são devidas à acção antrópica, urbano-portuária e, recentemente, à ocupação turística sem regras da praia-duna da Ponta do Ouro, com recuo médio de 0,95 a 1,75 $\mathrm{m} / \mathrm{ano}$ (na fronteira meridional do país). O recuo da linha de costa é acompanhado da submersão progressiva das plataformas anfíbias de grés costeiro, que, onde são mais extensas e largas, amortecem a erosão no litoral Índico. Na costa lodosa de mangal, verifica-se que o fenómeno transgressivo do sistema arenoso da praia submersa e da plataforma, sobre os solos lodosos do mangal, modifica a textura dos sedimentos superficiais das plataformas anfíbias, com consequências ecológicas evidentes na composição florística do mangal, onde as espécies helofíticas (Rhyzophora e Ceriops sps.) são substituídos pelas psamofíticas (Aviccenia marina).
\end{abstract}

Palavras-Chave: Moçambique, dinâmica litoral, taxas de erosão, elevação do nível médio do oceano na África Austral e Oriental.

Abstract - The dynamics of the SOUthern Mozambique coastal systems over THE PAST 30 YEARS. Erosion is the dominant process of Mozambique's coastal dynamics. In more than $90 \%$ of the coastline, it is a natural process that occurs as a consequence of tropical cyclones and of the recent relative sea level rise. The consequences of these processes are the retreat of the coastline and the occurrence

1 Investigadora do Centro de Estudos Geográficos e Professora Catedrática da Universidade de Lisboa. E-mail: m.albergaria@netcabo.pt 
of transgressive phenomena in all the sandy systems (beach-dune-lagoon). These are due to the erosion of the upper- and meso-tidal forms, such as beaches, dunes, spits, barrier islands and cliff fronts. At the same time, an infilling of the low coastal forms occurs that is due to the submergence of the sub- and meso-tidal forms, such as beachrock platforms (bio-erosion pools and solution benches filled with sand), estuarine bars and mudflats. Wherever the beachrock platforms are wide enough, despite being partially submerged, they preserve the erosion of the connected beachdune system. The salinization of the freshwater coastal aquifers, both in islands and in the mainland, and the growth of the coral reefs are two other consequences of this gradual submergence. The retreat values recorded in the beaches that experienced these natural dynamics in the southern coast of Mozambique range from 0.11 to $1.10 \mathrm{~m} /$ year over the last 31 years (1973-2004). However, the maximum erosion values of 0.95 and $1.75 \mathrm{~m} / \mathrm{y}$ took place in the southern border beach-dune system (Ponta do Ouro), and were due to disorderly exploitation by the tourist industry. The inland migration of the spit-dune system over the mangrove platforms has changed the sedimentation pattern, and the sand now overlaps the silt mudflats. For this reason, the mangrove flora has undergone ecological changes, such as the substitution of helophyte (Rhyzophora and Ceriops ssp.) by psammophyte species (Aviccenia marina).

Key Words: Mozambique, coastal dynamic, erosion rates, sea level rise in Southern and Eastern Africa.

Résumé - La dynamique des systèmes littorauX du sud du Mozambique PeNDANT LES 30 DERNIÈRES ANNÉES. L'érosion, aspect dominant de la dynamique actuelle sur le littoral du Mozambique, est due aux facteurs naturels sur $90 \%$ de son extension. Le passage des dépressions et des cyclones tropicaux, ainsi que l'élévation récente du niveau de la mer en sont les causes principales. La transgression océanique provoque le rétrécissement des plages, l'entaille des cordons dunaires qui migrent vers l'intérieur en envahissant les lagunes, la segmentation des cordons littoraux et des îles-barrières, le recul rapide des falaises vives et la réactivation des falaises mortes, la destruction des microformes de bio-érosion des plateformes sableuses de l'estran, le rétrécissement des mangroves, la salinisation des aquifères saumâtres des plaines littorales et des îles, et encore la croissance des récifs coralliens. On présente des exemples du littoral sud du Mozambique, où l'on a observé, entre 1971-1975 et 1999-2004, des taux moyens de recul de la ligne de côte, dus à la dynamique naturelle, de $0,11 \mathrm{~m} /$ an sur des plages abritées et de 1,10 m/an sur des plages exposées à l'ondulation. Mais les taux d'érosion les plus élevés résultent de l'action anthropique urbano-portuaire et, plus récemment, de l'occupation touristique sauvage de la plage et de la dune de Ponta do Ouro, à la frontière sud du pays, où le recul a été de 0,95 à $1,75 \mathrm{~m} / \mathrm{an}$. Ce recul est accompagné de la submersion progressive des plateformes amphibies de grès côtier qui, là où elles sont le plus larges, amortissent l'érosion océanique. Sur les côtes à mangrove, la transgression du système sableux de la page immergée et de la plateforme sur les sols argileux de la mangrove modifie la texture des sols superficiels des plateformes amphibies, avec des conséquences écologiques évidentes sur la composition floristique de la mangrove, où les espèces hélophytes (Rhyziphora et Ceriops sps.) sont remplacées par les psammophytes (Aviccenia marina).

Mots-clés: Mozambique, dynamique littorale, taux d'érosion, élévation du niveau de la mer en Afrique Australe et Orientale. 


\section{INTRODUÇÃO}

No extenso litoral de Moçambique podem individualizar-se três unidades morfo-litológicas cuja evolução depende, sobretudo, de processos litorais controlados pela dinâmica marinha (Fig. 1).

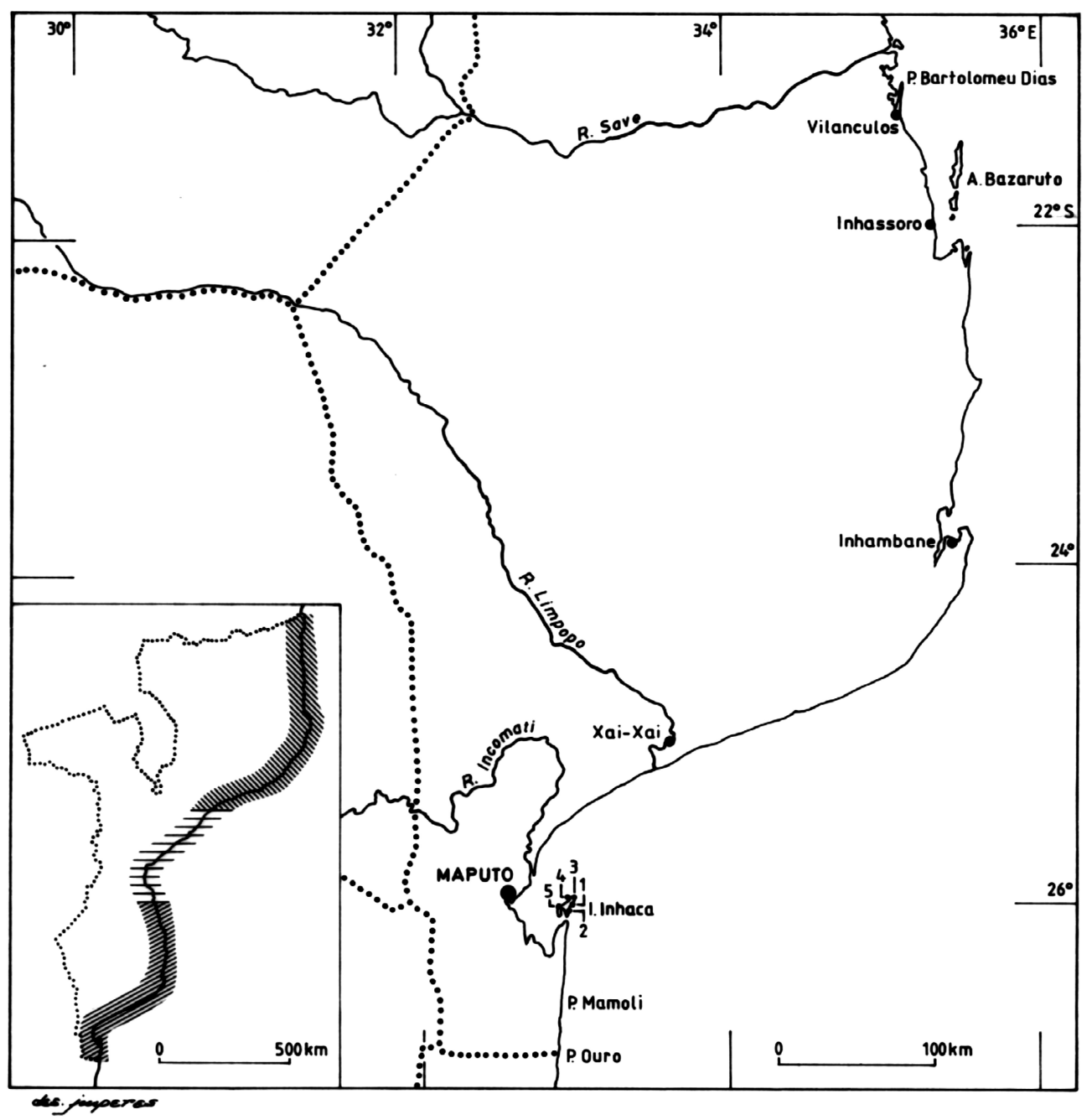

Fig. 1 - Localização das áreas de estudo e dos pontos onde se recolheram registos de erosão, no litoral do Sul. No encarte, localizam-se os três sectores geomorfológicos do litoral de Moçambique. N-Norte, C - Centro e S - Sul Fig. 1 -Location of study areas and sites in which records were made of erosion along the southern coastal area. The three geomorphologic sectors along Mozambique's coast can bee seen: $N$-North; $C$-Centre and $S$-South 
A região setentrional, entre a foz do rio Rovuma e o delta do Zambeze, caracteriza-se por uma faixa estreita, tectógena, na margem dos planaltos de Cabo Delgado e Nampula, dominada por arribas e praias anexas, com uma franja recifal e ilhas coralígenas na plataforma continental adjacente, também estreita. A região central, que compreende os deltas do Zambeze e do Save, corresponde a uma larga planície fluvio-marinha, baixa e areno-lodosa, onde dominam os processos ligados às correntes de maré. Ainda que nestas planícies pantanosas se possam incluir as do delta do Save, o delta do Zambeze, pela sua dimensão e morfodinâmica, constitui uma subunidade, onde os processos dominantes na dinâmica actual dependem da ondulação, tal como acontece na região setentrional. A região meridional, entre o delta do Save e a ponta do Ouro, na fronteira sul, é uma extensa planície arenosa, com praias anexas a arribas eoleaníticas, ou a sistemas de dunas, lagunas, ilhas-barreira e plataformas-barreira de grés costeiro (beachrock) que ocorrem no espraiado e na plataforma continental anexa. Esta planície, onde a extensão das dunas indica a importância dos processos eólicos, em conjunção com as variações do nível oceânico (desde o fim do Plioceno), só é interrompida pelos estuários, e continua-se, para sul, pela província do Kwazulu-Natal (República da África do Sul), onde termina, em Durban.

A estabilidade tectónica do litoral deveria ser considerada, devido à sua posição geográfica, por um lado, perto do limite da placa africana, por outro, situadas no bloco afectado pelos movimentos do sistema tectónico dos Grandes Lagos Africanos (rift). Também é de considerar a subsidência que afecta o sector central, especialmente no delta do Zambeze (fóssil e actual).

Este trabalho incide sobre a dinâmica actual da região Sul, que parece a mais estável, mesmo que admitamos a sua ligação à flexura oriental do continente africano (KING, 1972) ou ao sistema tectónico marginal, evidenciada pela cadeia dos Libombos e pelo grande afundamento das formações cretácicas, na plataforma continental (MARTIN e Fleming, 1986; LÄChelt, 2004). Porém, como aqui se trata da dinâmica da costa nas últimas três décadas, especialmente da erosão e das suas causas, sobretudo naturais, relacionadas com a passagem de depressões e ciclones tropicais e com a variação relativa do nível médio do oceano, não se discute a diferenciação das causas da sua variação recente, admitindo que esta é a resultante de fenómenos tectónicos e sedimentogénicos, e das variações climáticas de curta e longa duração.

\section{METODOLOGIA}

A variação da linha de costa foi observada a partir de trabalho de campo intensivo, realizado entre 1970 e 1975, e esporádico e mais localizado entre 1999 e 2004, tendo-se feito a análise comparativa de perfis de praia diacrónicos, em áreas de amostragem, das quais se retiraram os casos de estudo que se apresentam. Também se recorreu à comparação de fotografias aéreas e de fotogra- 
fias, especialmente usadas para analisar a evolução dos perfis das arribas eoleaníticas, a evolução das formas de pormenor que modelam a superfície das plataformas rochosas (formas em cogumelo, marmitas, vasques e lapiaz), as modificações da natureza da sedimentação, a evolução das áreas de mangal, e outras modificações relativas à posição de estruturas artificiais fixas, como acontece com os faróis, fortes e outras edificações costeiras. Quando disponíveis, foram analisadas algumas cartas hidrográficas, de que se salienta o Plano Hidrográfico da Ponta Vermelha à Inhaca, de 1941-43.

As observações de campo foram complementadas com análises sedimentológicas de areias, das quais se procedeu à análise dimensométrica, morfoscópica e litológica.

Ainda foram tomadas em conta algumas informações provenientes de relatos orais e escritos, dos quais se podem inferir modificações da costa, nos períodos colonial e pos-colonial. O recurso a imagens satelitais foi, por enquanto, posto de parte, pelo custo e dificuldade em obter imagens recentes com resoluções e alturas do nível da maré compatíveis com análises de pormenor. No entanto, no caso das ilhas da Inhaca e de Bazaruto, a comparação de duas imagens Landsat (TM) de 1985 e 1998, recolhidas em baixa-mar, pode fornecer elementos para a avaliação qualitativa das modificações da sedimentação arenosa pouco profunda nas plataformas e nos bancos anfíbios do espraiado.

\section{ANÁLISE DE CASOS DE ESTUDO}

A erosão é o processo da dinâmica litoral que ocorre em toda a costa moçambicana, embora com taxas diferentes. As causas antrópicas deste processo têm sido referidas desde o fim do século XIX (MoreIRA, 1984), e são evidentes em alguns sectores do litoral onde estruturas portuárias, molhes, pontões, muralhas, enrocamentos, aterros e diques, interromperam o abastecimento continental dos sedimentos e alteraram o balanço sedimentar, o sentido e a capacidade das correntes litorais. São os casos de alguns portos urbanos, como Maputo, Beira e Chinde. Na primeira metade do século XX, a destruição dos mangais também já fora apontada como causa da erosão nas fozes dos rios (MOREIRA, 1975a).

Outras causas indirectas, também antropógenas, podem ser consideradas, em especial as que incidem sobre o contrôlo do caudal dos rios com barragens, que retêm os sedimentos fluviais nas albufeiras, contribuindo para o défice em sedimentos na alimentação da plataforma continental. Porém, nos rios do Sul que têm barragens, como o Maputo, o Umbelúzi, o Incomáti, o Limpopo e o Save, o défice de sedimentos arenosos na foz não se regista, porque a jusante da última barragem, atravessam extensas planícies arenosas, em território moçambicano, ainda encaixados nos seus largos terraços arenosos. O facto mais grave é a planura dos seus perfis longitudinais no baixo curso, e o défice de escoamento com que chegam à foz, mais controlada pelo regime marinho que pelo 
fluvial. Só durante as grandes cheias há saída de sedimentos para a plataforma continental.

Nos rios do Sul, incluindo o Save (cujo leito moçambicano é o menos declivoso, depois do Maputo), o Limpopo e o Incomáti, após as cheias, as restingas da foz são encurtadas e emagrecidas, e os bancos arenosos dos deltas de maré são cortados, rebaixados e transportados para o largo (MOREIRA, 1984). Na sua maior parte, estes sedimentos são provenientes da planície de inundação do sector vestibular. Dos rios que desaguam na baía de Maputo (Incomáti, Matola, Umbelúzi, Tembe, Fúti e Maputo), o Incomáti, mais caudaloso, é a fonte mais importante de sedimentos arenosos.

As causas naturais da erosão do litoral são, indubitavelmente, as mais responsáveis pela evolução de toda a costa moçambicana, ainda só pontualmente urbanizada e modificada por estruturas pesadas. A prova é o acelerado recuo nos últimos 31 anos, de sectores de costa não afectados por nenhuma intervenção humana local ou regional, como aqueles onde se localizam os casos de estudo escolhidos, nomeadamente na ilha da Inhaca, onde foi possível encontrar exemplos de quase todos os impactes que ocorrem ao longo do litoral do país, possivelmente porque foi o lugar onde se recolheu informação mais abundante e mais detalhada. Por isso se inicia a apresentação dos casos de estudo de sul para norte, com excepção da Ponta do Ouro, onde as taxas de erosão são mais elevadas, mas sobretudo devidas à intervenção humana.

\section{Sistemas praia-duna, praia-arrriba, cordão litoral, mangal e recifes coralinos do arquipélago da Inhaca}

Fica situado entre $26^{\circ} \mathrm{S}$ e $33^{\circ} \mathrm{E}$, em frente à costa da cidade de Maputo, da qual está separado pela extensa baía do mesmo nome (fig. 1). A principal ilha, a Inhaca, é a continuação da península de Machangulo, da qual se encontra separada pelo canal de Santa Maria, possivelmente aberto durante um estádio da transgressão holocénica (SÉNVANO, REBÊLo e MARQues, 1997). A pequena ilha dos Portugueses, a NW da Inhaca, é baixa ( $8 \mathrm{~m}$ de altitude máxima) e corresponde a uma coalescência de cordões litorais e dunares baixos, intercalados com pântanos e mangal. As ilhas são exclusivamente sedimentares, formadas por areias e arenitos marinhos e eólicos, recifes coralígenos e lodos fluviomarinhos (BARRADAS, 1965; CARVALHO, 1975). Quase toda a costa oriental e setentrional, bem como parte da costa ocidental da Inhaca, encontra-se debruada por uma plataforma estreita de grés costeiro que se estende na faixa mesolitoral, cuja superfície se encontra modelada por microformas de bioerosão, das quais se destacam marmitas (mares, pools) e plataformas de dissolução escalonadas (vasques, solution benches) (CARVALHO, 1975; MoreIRA, 1983, 1996 e 2001). Na costa ocidental da ilha, abrigada, a plataforma de grés costeiro fossiliza parcialmente um recife de coral morto (CARVALHO, 1975), sobre o qual se desenvolvem novos recifes. 
O levantamento e a monitorização das formas litorais da ilha da Inhaca, em 1970-75 e em 2001 e 2002, não só possibilitou a definição das unidades geomorfológicas da ilha, como permitiu observar, directamente, vários impactes da elevação recente do nível oceânico. Toda a costa tem uma evolução natural, sem intervenções antrópicas, a não ser nos mangais e pântanos dos sectores baixos do norte e do centro da ilha, enxugados para produção de campos agrícolas e áreas habitáveis, em especial na década de 80 , quando a ilha serviu de refúgio, na guerra civil, para cerca de 10.000 pessoas. Em 1970, a ilha tinha menos de 1.000 pessoas.

Assim, os processos de erosão que afectam as praias não abrigadas pelas barreiras de grés costeiro são consequência das ondas e dos ventos de tempestade, e da elevação recente do nível do oceano.

A costa oriental é formada por uma única praia, quase rectilínea, anexa a um alto sistema dunar, directamente exposta à ondulação do oceano Índico, cujo regime anual é de sudeste a es-sudeste, gerada pelos alíseos, com 2 a $4 \mathrm{~m}$ de altura. A praia é orlada por uma plataforma de grés costeiro que a protege da rebentação, porque aflora em posição infra e mesolitoral. Mesmo assim, no perfil da praia na latitude do Monte Inhaca (fig.1-1), a taxa média de recuo foi de 0,11 m/ano, entre 1973 e 1999 (Quadro I). No extremo sudeste dessa praia, entre as dunas de Muamulungo e a ponta Torres, existe um troço em que não afloram grés costeiros, e a praia fica aberta à rebentação das ondas oceânicas (fig. 1-2). Aí, a linha de costa encurva num pequeno arco, e a praia contacta com a duna primária, com $44 \mathrm{~m}$ de altura, através de um sistema de dunas de praia alta que se movimenta e tende a cavalgar a grande duna. $\mathrm{O}$ trânsito longitudinal da areia, devido ao vento, que cria pequenas barcanes na praia alta, compensa a erosão da praia, nesse sector. A areia é de grão médio a grosseiro, na praia média e baixa, e de grão fino nas dunas da praia alta. $\mathrm{O}$ declive da praia atinge $8 .^{\circ}$ no degrau para a praia baixa, onde acontece a rebentação. É neste sector que se encontra a praia mais estreita da costa oceânica da ilha, com uma largura média de $115 \mathrm{~m}$ entre a base das dunas de praia alta e a linha de baixa-mar em marés vivas, entre 1973 e 1975. A largura da praia alta, entre as referidas dunas e a berma da praia em maré viva, variava entre 43, 44 e 47 $\mathrm{m}$, em três perfis levantados, na mesma linha, respectivamente em Setembro de 1973 e 1974 e em Março de 1975. Relatos de pescadores da ilha referem que as ondas geradas pelas tempestades ciclónicas atingem a base da duna, como aconteceu em 1964 (passagem do ciclone Claude) e em 2003 (Japhet). Em Setembro de1999 a praia encontrava-se muito mais côncava, mas estreita $(85 \mathrm{~m})$ e declivosa $\left(9^{\circ}\right)$, e as marcas da preia-mar atingiam a base das dunas de praia alta, sem que tivessem ocorrido tempestades ciclónicas nesse ano ou no ano anterior. No perfil de 1999, o degrau da berma distava $5 \mathrm{~m}$ da base da duna. A praia alta emagreceu 22 m entre 1973 e 1999, o que corresponde a uma taxa de erosão de $0,81 \mathrm{~m} / \mathrm{ano}$, a mais elevada que se observou na praia alta de todo o litoral da ilha, dada a situação particular da praia, numa abertura da plataforma arenítica). Essa perda, na praia alta, é a que mais importância tem no estreitamento da praia em todo o perfil, perdendo 1,10 m/ano (Quadro I). 
Quadro I - Taxas de erosão e recuo médio da linha de costa no Sul de Moçambique, entre 1970 e 2004.

Table I-Erosion rates and average recession of the shoreline in the South of Mozambique, between 1970 e 2004.

\begin{tabular}{|c|c|c|c|c|}
\hline & $\begin{array}{l}\text { Período de } \\
\text { observação }\end{array}$ & $\begin{array}{l}\text { Período de } \\
\text { comparação dos } \\
\text { registos } \\
\left(n .^{\circ} \text { anos }\right)\end{array}$ & $\begin{array}{l}\text { Taxa de recuo } \\
\text { médio em m/ano, } \\
\text { por causas } \\
\text { naturais }\end{array}$ & $\begin{array}{c}\text { Taxa de recuo } \\
\text { médio em m/ano, } \\
\text { por intervenção } \\
\text { humana }\end{array}$ \\
\hline $\begin{array}{l}\text { Ilha da Inhaca: } \\
\text { Costa E - farol }\end{array}$ & 1971- 2001 & 26 & 0,11 & \\
\hline $\begin{array}{l}\text { Ilha da Inhaca: } \\
\text { Costa SE - praia St. Maria }\end{array}$ & 1973 - 1999 & 30 & 1,10 & \\
\hline $\begin{array}{l}\text { Ilha da Inhaca: } \\
\text { Costa W (Museu) }\end{array}$ & $1971-2002$ & 31 & 0,30 & \\
\hline $\begin{array}{l}\text { Ilha da Inhaca: } \\
\text { Costa W (Instalações) }\end{array}$ & $1971-2002$ & 31 & 0,35 & \\
\hline $\begin{array}{l}\text { Ilha da Inhaca: } \\
\text { Costa N -farolim }\end{array}$ & $1971-2001$ & 30 & 1,05 & \\
\hline $\begin{array}{l}\text { Inhaca: } \\
\text { Porto do hotel, enrocamento }\end{array}$ & $1972-2002$ & 28 & & 0,71 \\
\hline Praia do Xai-Xai & 1971- 1999 & 28 & 0,25 e 0,36 & \\
\hline $\begin{array}{l}\text { Vilankulos-ponta de } \\
\text { Bartolomeu Dias }\end{array}$ & 1973- 2001 & 26 & 0,56 & \\
\hline Ponta Mamoli & $1972-2004$ & 32 & 0,24 & \\
\hline Ponta do Ouro & 1970- 2004 & 30 & & 0,95 e 1,75 \\
\hline
\end{tabular}

Ainda na costa oceânica, no sector nordeste, num perfil localizado a sul do cabo Inhaca (fig. 1-3), onde a rebentação das ondas se faz contra a cornija exterior da plataforma de grés costeiro, a largura da praia aumentou de $11 \mathrm{~m}$ entre 1975 e 1999 (+ 0,47 m/ano) e de 12,8 m entre 19975 e 2002 (+ 0,47 m/ano). Esse aumento, que correspondeu também a uma acentuação da concavidade da praia alta, deveu-se à progressão das dunas de praia alta para o interior; estas dunas triplicaram a sua altura, alimentadas por areais provenientes da deflação longitudinal de sul, ao longo da praia, e formaram um sistema que coalesceu e cavalga o flanco da primeira duna e aumenta a praia alta. A erosão marinha foi mais eficaz no desmantelamento das marmitas mesolitorais inferiores, no biselamento dos rebordos das vasques (MOREIRA, 1983) da plataforma de grés costeiro e na destruição da cornija da arriba eoleanítica da ponta Mazondoé, que em 1975 formava uma saliência superior a um metro, e em 2002 constitui um enorme bloco caído sobre a plataforma.

Na costa norte (fig. 1-4), a ocidente das dunas orientais, a planície litoral é limitada por um cordão litoral baixo ( $3 \mathrm{~m}$ de altitude máxima) que se prolonga, para ocidente pelo banco de Sengala, até à ilha dos Portugueses, e para norte pelo grande banco arenoso que se estende sobre grés costeiro, até ao baixo Danae (Plano Hidrográfico da Ponta Vermelha à Inhaca, 1941-44). O grés costeiro aflora na faixa mesolitoral, com marmitas de bio-erosão sobrelevadas de cerca de 30 a $50 \mathrm{~cm}$ acima das superfícies de dissolução (CARVALHO, 1975), 
na qual se encontram embutidas outras marmitas com rebordos bioconstruidos (MOREIRA, 1983). Em 1999 e 2002, toda a plataforma rochosa apresenta vestígios de submersão e assoreamento: no limite externo que se desmantelou, no biselamento dos rebordos das marmitas baixas, e no entulhamento das marmitas e vasques, por areia fina (proveniente da plataforma anexa, porque a superfície dos grãos de quartzo é brilhante). Enquanto isso acontece, a erosão da corrente vinda do Índico escavou a praia anexa ao banco, provocando o recuo da linha de costa, a ponto do farolim a ocidente da ponta Mazondoé, instalado no cordão litoral do banco de Sengala, presentemente se encontrar em plena faixa mesolitoral, com a base coberta de água durante as preia-mares, mesmo em águas mortas. O recuo da costa foi de 1,05 m/ano, entre 1974 e 2001; porém, dadas a morfologia plana e a suficiente alimentação arenosa, não se verifica estreitamento nem da praia nem do cordão litoral, porque todo o sistema praia-cordão litoral migra transgressivamente sobre as plataformas lodosas do mangal, cobrindo-as sem impedimento. A modificação da textura dos sedimentos na superfície do solo do mangal tem, por sua vez, consequências na dinâmica ecológica deste sistema, com alterações da composição florística. As espécies francamente helófitas, como as dos géneros Rhyzophora e Ceriops, vão reduzindo a sua área de distribuição, em abono da psamofílica Aviccenia marina. Por seu lado, a acumulação vertical de areia sobre o mangal, compensa o efeito de submersão.

Na costa ocidental da ilha, abrigada da ondulação oceânica, as praias são rasas, de areias finas, anexas a arribas talhadas em arenitos mal consolidados. Desde o Portinho até à ponta Ponduíne, cobrem um banco de coral que localmente aflora nas baixa-mares vivas. A ondulação que atinge a base das arribas é fraca (em regra menos de $1 \mathrm{~m}$ de altura), mas suficiente para escavar pequenas sapas que instabilizam o equilíbrio das areias e arenitos sobrejacentes. No entanto, entre 1975 e 1999 verificou-se um estreitamento, de entre 12 e $22 \mathrm{~m}$, em dois perfis feitos no sector da praia alta em frente ao Museu de Biologia (respectivamente a norte da entrada para o Museu (fig. 1-4), e a Sul da entrada para as instalações dos visitantes (fig. 1-5), onde, em preia-mar de águas vivas, a praia alta tem entre 2 a $5 \mathrm{~m}$ de largura. Apesar da posição abrigada, o recuo da linha de costa arenosa é muito acentuado, com valores de $0,5 \mathrm{~m}$ a $0,91 \mathrm{~m} / \mathrm{ano}$ (Quadro I). A praia baixa, com mais de $1 \mathrm{~km}$ de extensão, aparentemente não mostra modificações, embora os colectores de mariscos sobre o recife coberto de areia e prados marinhos, afirmem que já não chegam, a pé, perto do limite exterior da praia, nem nas marés mais baixas do ano, mesmo com mar calmo, porque já não conseguem manter-se de pé, nem prospectar o fundo com o arpão, como fazia a geração dos progenitores. A submersão é, assim, evidente.

Na ponta Ponduíne, formada por um arenito bem consolidado, nota-se um ligeiro escavamento da base (mais por bio-erosão do que por erosão mecânica), e vestígios do desabamento da cornija supralitoral bem avançada em 1975. Na plataforma anexa, de grés costeiro muito duro (MOREIRA, 1983), as formas em cogumelo, mesolitotais, viram desmoronar parte das abas rochosas. 
Na costa meridional, que forma uma baía em saco (o chamado Saco da Inhaca), ocorre um outro fenómeno que pode ser considerado consequência da elevação relativa do nível oceânico. Trata-se da expansão dos recifes coralinos que crescem nas orlas areníticas e sobre a superfície arrasada de um antigo banco de coral, escavada em marmitas e submersa a cerca de um metro. Em 1975 eram raras as colónias de polipeiros sobre a plataforma submersa, encontrando-se sobretudo dentro das marmitas mais fundas. Actualmente, ocorrem com frequência e maior diversidade específica, tanto sobre a plataforma recifal como nas escarpas rochosas submersas da ponta Torres. O estatuto de preservação ecológica deste banco de coral, efectivamente controlado, também contribui para justificar o seu desenvolvimento recente.

Na planície litoral do norte da ilha e na da depressão entre os cordões dunares oriental e ocidental, a salinização progressiva da água salobra dos aquíferos pode ser considerada como um impacte da elevação do nível do oceano. No entanto, nas últimas duas décadas o grande aumento da população da ilha, e, consequentemente, do consumo da água salobra dos poços, foi, certamente o maior causador da subida da água salgada.

A ilha dos Portugueses encontra-se em erosão nas praias expostas a norte, a leste e a oeste, onde se evidencia o estreitamento ou desaparecimento da praia alta. Entre as duas ilhas, o banco de Sengala cresceu em altura e largura, alimentado pela areia proveniente da erosão das praias e transportada pela deriva litoral de leste, inflectida na ponta Mazondoé. Também aqui, os impactes da submersão recente são localmente anulados pelo balanço sedimentar positivo.

\section{Sistema praia-duna do Xai-Xai}

A praia do Xai-Xai situa-se a norte da foz do rio Limpopo, num sector da costa com direcção nordeste-sudoeste, perpendicular à direcção dos ventos alíseos. Encontra-se abrigada da ondulação oceânica por uma plataforma estreita de grés costeiro que se encontra sob a duna em que está entalhada a arriba actual, e aflora, paralelo à costa, em posição de quebra-mar mesolitoral. Na praia, abstraindo as construções nas dunas da praia alta, que já existiam em 1973 e que proliferaram até 2003 (data da última visita ao terreno), não se notou significativa alteração do perfil, nos últimos 30 anos, pelo facto de se encontrar protegida por três plataformas paralelas de grés costeiro, que provocam a quebra da onda muito ao largo. O afloramento mais interior protege completamente a praia. Neste, porém, observaram-se testemunhos de intensa erosão, reflectidos no desmantelamento das marmitas mesolitorais inferiores e das vasques, e ainda no aplanamento das lapiaz de arestas cortantes que se desenvolvem na parte mais alta e interior da plataforma rochosa (MoreIRA, 1983). Ainda se observaram fenómenos de colapso da cornija interior da plataforma e de abertura de numerosas fendas transversais, por onde se escoa a água, no fluxo e refluxo, subescavando a areia onde assenta o recife rochoso (com cerca 
de $3 \mathrm{~m}$ de espessura) e provocando o colapso dos blocos segmentados. Na face exterior, em vez da praia baixa plana, existe um sulco escavado de cerca de $2 \mathrm{~m}$ abaixo do limite inferior do afloramento rochoso, largo, por onde se escoa uma deriva que transporta areias e conchas partidas, para norte.

A mais intensa erosão verificada nesta praia do Xai-Xai, incide no local onde o afloramento do grés costeiro aparece, sob a duna recente; a arriba arenosa, subvertical, e sem qualquer vegetação, encontra-se completamente instabilizada, porque é atingida em todas as preia-mares. Em fotos de 1974, esta estreita plataforma de grés costeiros aflora sob a areia da duna, mas distante de alguns metros, para o interior, da frente da arriba arenosa, e ambos anexos a uma praia baixa plana. Certamente se verificou intensa erosão que fez recuar a frente da arriba e desmantelou o afloramento de grés costeiro, permitindo à deriva aproximar-se da costa, e escavar, contra o recife rochoso, uma praia baixa com sulcos e cristas que nunca emergem, típicos de praia exposta, reflexiva. $\mathrm{Na}$ ausência de escala rigorosa das fotos, apenas se sugere, para a frente da arriba, um recuo de 7 a $10 \mathrm{~m}$ em 28 anos, o que equivale a uma taxa média de erosão de 0,25 a $0,36 \mathrm{~m} / \mathrm{ano}$.

\section{Sistemas praia-arriba do Inhassôro e restinga de Bartolomeu Dias}

Este sector da costa, situa-se a norte de Vilankulos (ou Vilanculos), onde a costa é formada por um sistema de praia estreita anexa à arriba talhada nos arenitos vermelhos, e, a norte de Inhassôro forma uma península com direcção sul-norte, entre o oceano e o curso terminal do rio Govuro. A península corresponde à restinga de Bartolomeu Dias, onde os cordões litorais são coroados por formas dunares de areia branca. Ao longo da berma da praia aflora uma formação de grés costeiro pouco consolidado, que se estende até à extremidade da restinga, a ponta de Bartolomeu Dias (MoreIRA, 1975 b).

Ao longo desta costa, directamente aberta ao oceano, e com traçado na direcção norte-sul, já entre 1973 e 1975 se observavam fenómenos de acelerada erosão, com o reactivar do sapamento na base das arribas mortas a norte de Inhassôro, que, a partir da plataforma somital, evoluíam por processos de abarrancamento (até formar campos de bad-lands; MoREIRA, 1975 b). Em 1999, a erosão parece ter-se intensificado, para norte, com a destruição das pequenas dunas da praia alta, e o entalhe da arriba numa duna branca recente, que já havia soterrado uma mata de casuarinas, cujos troncos mortos, emergiam, in loco, exumados da duna pela erosão das ondas tempestuosas, desde 1964 (ciclone Claude). A praia dos troncos das casuarinas plantadas nos anos 30 do século XX (MoreIRA, 1984) desapareceu, e a arriba vai sendo escavada na duna, de modo a desenraizar algumas jovens casuarinas, cujos troncos verdes caem na base. A destruição da vegetação natural (mato de restinga) entre 1980 e 1995, acelerou muito o recuo da costa. O fenómeno transgressivo que causava a migração do sistema praia-duna para o interior, já era, então, uma realidade observável com impactes morfogénicos eficazes. 
A primeira florestação da península de Inhassôro-Bartolomeu Dias datará desse período (1930-60). Admitindo essa data inicial, em cerca de 30 anos, assistiu-se à progressão de todo um cordão dunar, em direcção a ocidente (ao vale do Govuro), com soterramento da mata de casuarinas, cujos troncos, em 1974 continuavam a surgir, de pé, na praia alta (MOREIRA, 1975 b). Mais 40 anos, a mata desapareceu (por causas naturais e para exploração de madeira e carvão), e o cordão dunar holocénico, de areias brancas, atinge o vale do rio Govuro, cujo mangal helófito assoreia, ajudado pela seca progressiva.

$\mathrm{Na}$ extremidade norte da península, em 1973 eram frequentes as marcas de fenómenos de galgamento ocorridos durante as tempestades, e os arbustos da vegetação dunar da extremidade da restinga estavam a ser desenraizados ou soterrados, bem como as árvores do mangal do Govuro, no lado abrigado daquela. A segmentação da restinga, já anunciada pelas cicatrizes dos galgamentos de 1964, foi uma realidade que ocorreu em 2003, durante a passagem do ciclone Japhet. Na ponta, a restinga encurtou cerca de 14 metros, entre 1974 e 1999, o que equivale a uma taxa média de recuo de $0,56 \mathrm{~m} / \mathrm{ano}$. Por informação dos pilotos que voam entre Vilankulos e Bazaruto, em Março de 2003 a restinga fragmentou-se, deixando 3 canais na extremidade; em 2 deles, no Outono de 2004, já foi possível a passagem a vau nas baixa-mares de Setembro. Mas no da ponta, mais aprofundado pela corrente, passou a ser o mar que envolve a nova extremidade, com um pequeno banco de areia que não voltou a emergir, e que se espalha e afasta para norte. $\mathrm{O}$ efeito erosivo das ondas e ventos de Japhet, cujo centro passou sobre a área, não foi recuperado, nem na costa continental, nem das ilhas do arquipélago de Bazaruto.

Talvez a elevação do nível do oceano, entre 0,5 e $1 \mathrm{~m}$, num futuro próximo (Titus e NARAYANAN, 1995), comprometa a recuperação sazonal da dinâmica costeira, cujos mais desastrosos surtos erosivos se verificam durante a passagem das depressões e ciclones tropicais. Futuras observações com medidas de perfis de praia, poderão elucidar sobre as taxas da erosão actual, e prever os cenários da futura linha de costa moçambicana.

\section{Sistema praia-duna da Ponta do Ouro}

A ponta do Ouro é uma saliência da costa situada a poucos metros a norte da linha de fronteira entre Moçambique e o Kwazulu, na República da África do Sul, a cerca de uma centena de quilómetros de Maputo e a mais de três centenas de Durban. A ponta corresponde a um entalhe numa arriba eoleanítica, anexa a uma plataforma rochosa de eoleanito e grés costeiro, que se encontra modelada por formas de bio-erosão (MoreIRA, 1983 e 1996). A norte da ponta estende-se uma praia de areia média a fina, bem calibrada, quártzica, com $4 .^{\circ}$ a $6 .^{\circ}$ de declive médio, respectivamente nos sectores alto e médio, com orientação norte-sul, ligeiramente arqueada, e sem qualquer afloramento rochoso. Era, entre 1970 e 1975, uma praia com dinâmica natural, directamente exposta à 
ondulação oceânica, modelada em crescentes assimétricos entre Janeiro e Março, e em degraus, entre Junho e Novembro, quando a ondulação incide de es-sudeste ou mesmo de leste.

Entre 1972 e 1975 a largura média da praia alta, observada no máximo da enchente de marés vivas, foi de $53 \mathrm{~m}$ num perfil a cerca de $500 \mathrm{~m}$ para norte da ponta. Na mesma situação de maré, e no mesmo perfil, em 2004, a largura de toda a praia-baixa e meia e alta, era de $43 \mathrm{~m}$, e a praia alta não existe. No espaço das dunas de praia alta e da primeira duna, terraplanados, está uma cabana palafita com material de desportos aquáticos. Na face norte da ponta, a duna foi instabilizada por destruição da base (trilho de barcos) e recuou cerca de $55 \mathrm{~m}$, encontrando-se em rampa de limite de equilíbrio da areia fina, sem vegetação. Por sua vez, a areia resultante assoreou e fossilizou todas as formas de bio-erosão da plataforma anfíbia; a ponta eoleanítica desabou, recuando de $6,5 \mathrm{~m}$. O parque de campismo foi construído sobre as dunas terraplanadas. E todo o arco da praia tem construções pesadas (residências) sobre a duna primária. De toda a costa moçambicana, é o lugar em que maiores transformações se efectuaram, com as mais altas perdas de território emerso, em 30 anos, e onde maior foi a taxa de erosão. Tendo em conta as minhas observações, a taxa média de erosão variou entre 0,95 e 1,75 m/ano (Quadro I). A avaliar por fotografias de colegas sul-africanos, em 1999, o cenário era próximo do actual. Acrescente-se que, talvez $90 \%$ das transformações foram realizadas por sul-africanos, que exploram o turismo balnear e aquático da praia da Ponta do Ouro, onde a acessibilidade gratuita a um espaço público é vedada (facto verificado por nós em Outubro de 2004).

A grande erosão verificou-se na praia alta, que hoje se encontra sobre o espaço da duna primária dos anos 70 do século XX, como se comprova da comparação das fotografias de 1974 e 2004. Numa estimativa, porque o ponto de referência interior dos perfis de 1972, 73 e 74, desapareceu, a taxa de recuo da praia alta foi superior a 1,75 m/ano, até desaparecer numa rampa arenosa, inclinada e estreita, entre a duna primária (atingida pela rebentação em tempestade) e praia baixa. Ao ter em consideração os relatos dos pescadores da ponta Mamoli e de pessoas do Zitundo, e a informação de colegas da universidade do Natal (Durban), as grandes transformações deste lugar ocorreram na década de 90 do século XX, pelo que a taxa de erosão anual duplica.

Terraplanagens, abertura de vias de passagem de viaturas $4 \times 4$, pela praia, construção pesada, deslocação e concentração de viaturas de tracção $4 \times 4$ com barcos atrelados que circulam ao longo e através da praia, tracção de equipamentos de mergulho e de outros desportos náuticos, na última década, contribuíram para a paisagem actual. Aqui, a componente da erosão natural da dinâmica marinha, verificada na restante costa entre a ponta do Ouro e a ponta do Machangulo, dilui-se. O único valor disponível, é um recuo médio da praia, de $0,24 \mathrm{~m} / \mathrm{ano}$, entre 1972 e 2004 , no sector mais encurvado da praia, logo a norte da ponta Mamoli, onde o grés costeiro deixa de aflorar e a erosão da deriva de sul é difractada pela ponta, correspondendo ao lugar com mais elevada possibilidade de erosão. 


\section{CONCLUSÃO}

Dados os valores obtidos para as taxas médias de recuo da linha de costa nos locais referidos, apresentados no Quadro I, a erosão intensa foi o processo que dominou a evolução do litoral do sul de Moçambique, nos últimos 26 a 31 anos. Em condições de dinâmica natural, na costa directamente exposta à ondulação oceânica, os valores médios da taxa de recuo variam entre $0,11 \mathrm{e}$ $0,36 \mathrm{~m} / \mathrm{ano}$, em praias abrigadas da rebentação por afloramentos de grés costeiro, e entre 0,56 e 1,10 m/ano, nas costas abertas à ondulação. Nas praias abrigadas, da baía de Maputo, mas sem quebra-mar natural, a taxa de recuo é de cerca de 0,30 a $0,35 \mathrm{~m} / \mathrm{ano}$, superiores ou semelhantes às taxas de erosão protegidas pelo grés costeiro. Valores como os verificados na Ponta do Ouro, de $1,75 \mathrm{~m} / \mathrm{ano}$, correspondem a uma intensa intervenção humana que potencializa a erosão.

Este fenómeno, da erosão das praias, que ocorre devido a processos puramente naturais, só pode ser consequência de um movimento transgressivo do mar, já notado desde o início do século XX nas praias entre o Xai-Xai e o estuário do rio Limpopo, onde a praia desaparecia e as dunas avançavam sobre os corredores interdunares, onde se encontravam os solos produtivos. A submersão progressiva dos sectores da praia baixa não facilita a migração dos sistemas arenosos de praia-duna para o interior, a não ser quando o balanço sedimentar local é positivo e a topografia o permite; isso acontece ao longo das grandes extensões de praia (em comprimento), onde o fetch é suficiente para a deslocação longitudinal de areia, pelo vento. É a esse fenómeno que se atribui a engorda das dunas de praia alta, e, em certos casos, o seu cavalgamento pelos flancos da duna primária, em cunhas ou através de corredores de deflação no flanco exposto da duna. Nas restingas e nas estreitas ilhas-barreira, são numerosos os fenómenos de galgamento pelas ondas, mais relacionados com a passagem das tempestades ciclónicas. Nos sistemas dunares, o galgamento pelas areias eólicas pode atingir o corredor interdunar entre a primeira e a segunda duna, onde, em regra, existem lagunas que se encontram em processos de assoreamento e segmentação.

\section{BIBLIOGRAFIA}

BARRADAS, L. (1965) - Rochas do quaternário da beira-mar (Sul de Moçambique). Mem. Inst. Invest. Científica Moçambique, série B, 7: 37-84.

CarvalHo, G. S. (1975) - Notice on sedimentological, chronostratigraphic and geomorphological problems of Inhaca Island. Mem. Inst. Invest. Científica Moçambique, série B, 10: 51-71.

KING, L. (1972) - The coastal plain of Southeast Africa: its form, deposits and development. Zeitschrift fur Geomorphologie, N.F. 16: 239-251.

LÄchelt, S. (2004) - Geology and mineral resources of Mozambique. Maputo Direcção Nacional de Geologia: 514 p. 
Martin, A.K.; Fleming, B.W. (1986) - The Holocene shelf sediment wedge of the South and the East Africa. In R.J.KNight; J.R. McLean, eds, Shelf sand and sandstones, Canadian Society of Petroleum Geologists Memoir, II: 27-44.

Moreira, M.E.S.A. (1975a) - Nota sobre o ecossistema do mangal no sul de Moçambique. Garcia de Orta, Série Geografia, Lisboa, 4(1-2): 29-44.

MoREIRA, M.E.S.A. (1975b) - Inhassoro e Bartolomeu Dias: As actividades da população e a organização do espaço. Mem. Inst. Invest. Científica de Moçambique, Lourenço Marques, Série B, 10:197240.

MoREIRA, M.E.S.A. (1983) - Modelado cársico das arribas e plataformas de abrasão corrosão, no litoral sul de Moçambique. Finisterra-Revista Portuguesa de Geografia, XVIII(36): 223-291.

MoreIRA, M.E.S.A. (1984) - Ritmos da evolução geomorfológica da foz do Limpopo. In: Livro de Homenagem a Orlando Ribeiro, Centro de Estudos Geográficos, Lisboa, I: 315-320.

Moreira, M.E.S.A. (1996) - Bio-erosional forms in the beachrock reefs at coasts of Mozambique and Brazil. Zeitschrift für Geomorphologie, N. F., Suppl. Bd. 102: 151-167.

MoreIRA, M.E.S.A. (2001) - Síntese da evolução geomorfológica da ilha da Inhaca (Moçambique). In Moreia, Moura e Granja, edit. Homenagem (in Honorium) Professor Gaspar Soares de Carvalho, Braga: 137-158.

Plano hidrográfico da PONTA VERMElHa À INHACA (BAÍA DE LOURENÇO MARQUes) (1941-1944) - Folha 497, Escala 1: 75 000. Lisboa, Ministério das Colónias, Junta das Missões Geográficas e de Investigações Coloniais, Missão Hidrográfica da Colónia de Moçambique, 31.

SÉnvano, A.; Rebêlo, L.; Marques, J. (1997) - Notícia explicativa da Carta Geológica da Ilha da Inhaca (escala 1:25 000). Maputo, Ministério dos Recursos Minerais e Energia, Direcção Nacional de Geologia.

Titus, J.G.; NARAYANAN, V.K. (1995) - The probability of sea level rise. U. S. Environmental Protection Agency: 186p. 